\title{
A DIAGNOSTIC APPROACH FOR CALCULATION OF THRESHOLD POINTS OF A PR CONTROLLER FOR SINGLE-PHASE GRID CONNECTED PV SYSTEM
}

\author{
Deepika K.K. ${ }^{1}$, Vijayakumar J. ${ }^{2}$, Kesava Rao G. ${ }^{3}$, A. Venkatesh ${ }^{4}$ \\ and Debnath Bhattacharyya ${ }^{5}$ \\ ${ }^{1}$ Dept. of EEE, Vignan's Institute of Information Technology, Visakhapatnam, \\ Andhra Pradesh, India \\ ${ }^{2}$ Dept. of EEE, ANITS, Visakhapatnam, Andhra Pradesh, India \\ ${ }^{3}$ Dept. of EEE, KLEF, Vaddeswaram, Andhra Pradesh, India \\ ${ }^{4}$ Dept. of EEE, Vignan's Institute of Information Technology, Visakhapatnam, \\ Andhra Pradesh, India \\ ${ }^{5}$ Computer Science and Engineering Department, \\ Vignan's Institute of Information Technology, \\ Visakhapatnam-530049, India \\ ${ }^{1}$ kkdeepika18@gmail.com, ${ }^{2}$ jvkeee@gmail.com, ${ }^{3}$ deanvoice@yahoo.co.in, \\ 5 debnthb@gmail.com
}

\begin{abstract}
Proportional plus Resonant controller is presented as the injected grid current regulator applied to a single-phase grid connected inverter. This paper establishes a systematic approach to design the gains of the PR controller by determining its minimum and maximum threshold points, to achieve improved transient and steady-state performance. Extensive simulations are carried out by varying system parameters and their effects on magnitude and bandwidth of the amplitude-frequency response are explained.
\end{abstract}

Keywords - Current control, resonant controller, Grid-connected

\section{INTRODUCTION}

With the rapid increase in energy consumption, greener technologies like wind, photovoltaic, fuel cells are in widespread demand [1]. Thus, various topologies of power converters in Distributed Power Generation have been of great research interest [2][3]. The purpose of this converter is to synchronize and transfer the generated variable power to the grid based on a control algorithm. While selecting the controller to meet these requirements, an optimal balance between cost, computational complexity of the control and quality of waveform must be made [4]-[8].

For single-phase system, among the various controllers available [9][10], though PI controllers are simple, easy to realize and linear, they are susceptible to steady-state errors while tracking alternating input quantities [11][12]. Any variations have been suggested [13]-[16], but they deteriorate the bandwidth, stability limits of the system and introduction of harmonics into line currents [17]-[20]. Amongst the current control methods in voltage source converters, accuracy in the system modelling plays a vital role

Received: March 25, 2019

Reviewed: June 5, 2019

Accepted: June 25, 2019 
in Model-predictive control [21][22]. Whereas in hysteresis current control [23], switching rate and high frequency cause hindrance to achieve zero steady-state error. Thus, to achieve precise control of a single-phase converter in reference tracking, with reduced computational burden and same frequency response characteristics, a PR controller was introduced in [24] and several applications of PR controller for voltage source converters is detailed in [25]. In [26], PR controller is implemented using Infinite Impulsive Response (IIR) digital filter and details about the design of filter coefficients, to make the controller adaptive to the frequency variations.

Design of the gains any single-phase or three-phase PR controller may be performed by anyone of the methods internal model control, Bode plots or nyquist plots. In [27], gains of the resonant controller are generalized with respect to the closed loop bandwidth of the system. The analysis is carried out in $\alpha \beta$ frame and is applied to design the controller for a weak grid. Shift-operator digital implementation based on Tustin Transform is discussed in [28]. a and b coefficients involved in the z-domain equation of the controller are derived. In [29], PR controller is implemented for current control in a single-phase PV system based on a pseudo synchronous d-q transformation technique. Gains of the controllers are selected based on theory. In [30], standard transfer functions for PR controllers is proposed and methods to obtain the gains are presented. These are applied to some test cases and performance is compared to the tuning methods of PI controller. In [31], PR controller is realized in $\alpha \beta$ reference frame, to study the control of positive and negative sequence currents during fault conditions. Here the $\mathrm{Kp}$ and $\mathrm{Kr}$ values are given directly as 71 and 6000 respectively. It is observed that tuning of the controller gains while maintaining a trade-off between the various control parameters can be achieved when an appropriate range of the gains is provided. In this paper a systematic approach to design the gains of the PR controller by determining its minimum and maximum threshold points is explained in detail.

\section{DESIGN OF PR CONTROLLER}

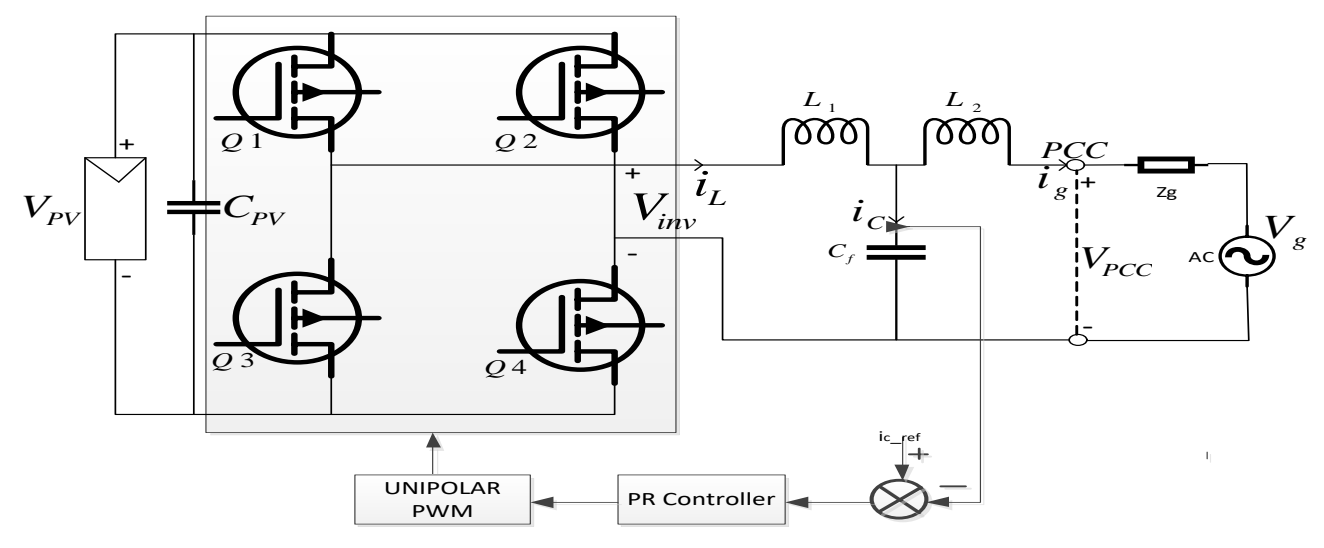

Fig. 1 Single-stage Circuit of Single-Phase VSC with PR controller connected to Grid

Current and voltage of solar panel are measured and fed to MPPT algorithm, to track the maximum point of the PV array. Based on the output of the MPPT and Phase Locked Loop (PLL), DC-AC inverter produces a current signal to be injected into the grid. Outer DC link voltage control loop generates the reference current for the inner current control loop. As reference current signal is a sinusoidal quantity, so there is a need for an ac compensator. Main objective of an ac compensator is to obtain zero phase and magnitude error. For an input Dc signal, PI controller meets this objective. Whereas, to meet the same objective with an input ac signal, dc compensator (transfer function $\mathrm{H}_{\mathrm{DC}}(\mathrm{s})$ ) must be converted to an equivalent ac compensator (transfer function $\mathrm{H}_{\mathrm{AC}}(\mathrm{s})$ ) maintaining the 
same bandwidth and frequency response [32]. This is accomplished by shifting the frequency to $\omega_{0}$, as :

$$
H_{A C}(s)=H_{D C}(s)\left(\frac{s^{2}+\omega_{1}^{2}}{2 s}\right)
$$

When applied to a PI controller, it can be represented as:

$$
H_{A C}(s)=K_{P}+\frac{2 K_{i} s}{s^{2}+\omega_{1}^{2}}
$$

where $K_{P}$ : Proportional gain, $K_{r_{3}}$ Resonant gain. Its frequency response is shown in Fig. 2. This lead to the to an ideal P+ Resonant controller. It is observed that, it can be realized with a proportional term and an integrator. Ideal dc integrator is approximated to a high gain low-pass filter with $\omega_{b}$ as the lower breakpoint frequency, gains $\mathrm{K}_{\mathrm{r}}$ and $\mathrm{K}_{\mathrm{p}}$ govern the amplitude gain and controller dynamics respectively. Accordingly, the response modifies to as shown in Fig. 3 and ac PI compensator in Eq. (2) is modified to give a finite gain, represented as:

$$
H_{A C}(s)=K_{P}+\frac{2 K_{r} \omega_{b} s}{s^{2}+2 \omega_{b} s+\omega_{1}{ }^{2}}
$$

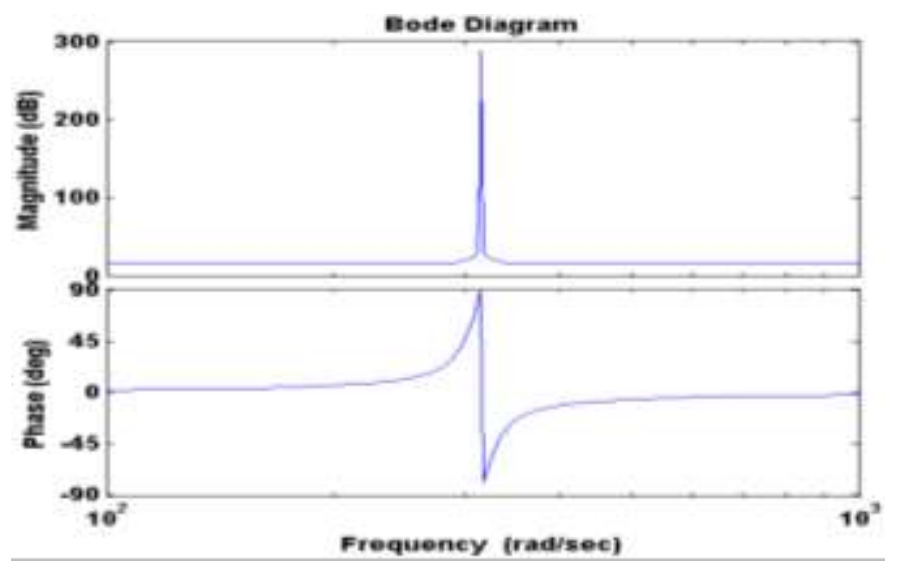

Fig. 2 Frequency response of an ideal PR controller

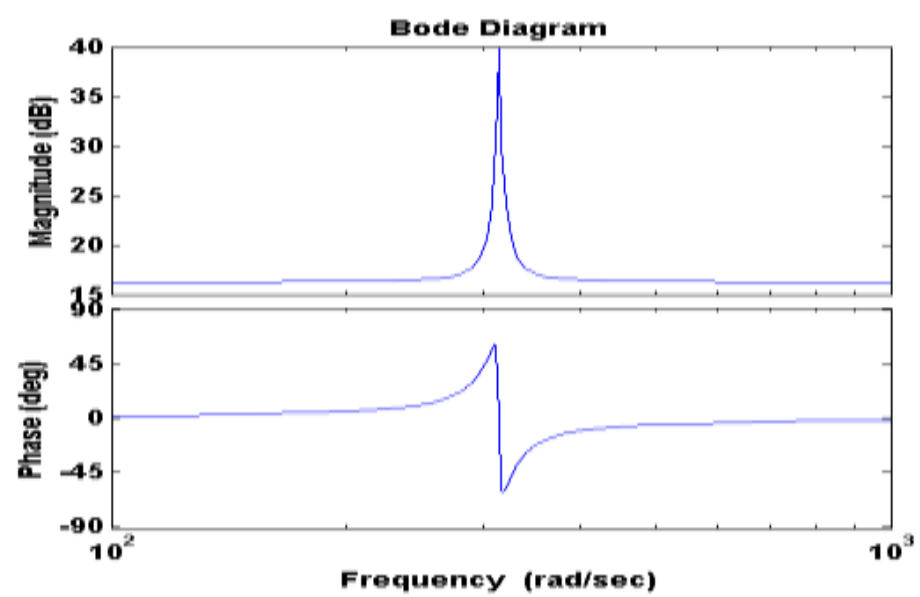

Fig. 3 Frequency response of a non-ideal PR controller 


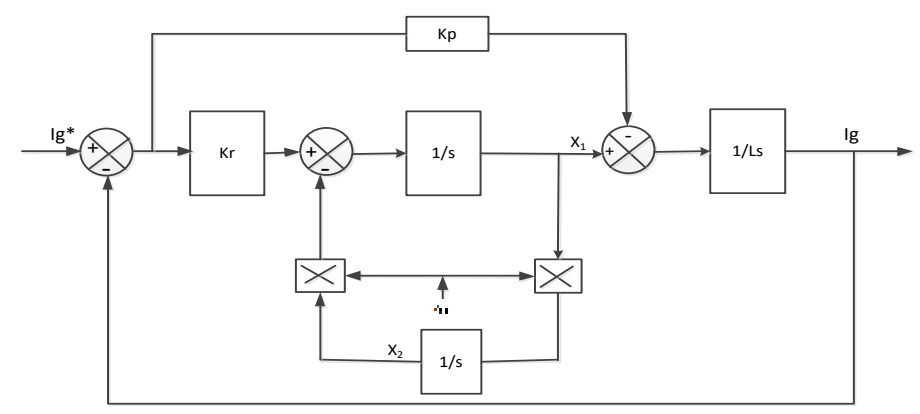

Fig. 4 Overall scheme for control of injected current

At fundamental frequency, magnitude-frequency response of the system is zero and is expressed as:

$$
20 \log \left|\left(\frac{2 K_{r} \omega_{b}\left(j \omega_{c)}\right.}{-\omega_{c}^{2}+2 \omega_{b}\left(j \omega_{c}\right)+\omega_{1}^{2}}\right) \frac{1}{j \omega_{c} L}\right|=0
$$

As $\omega_{c}>\omega_{1}$, by successive approximations Eq. (4) becomes:

$$
\begin{aligned}
& 20 \log \left|\frac{K_{P}}{j \omega_{c} L}\right|=0 \\
& K_{P}=\left|j \omega_{c} L\right| \\
& \frac{i_{g}{ }^{*}-i_{g}}{i_{g}{ }^{*}}=1-\frac{G(s)}{1+G(s)}
\end{aligned}
$$

At fundamental frequency, steady-state error in injected grid current is considered as $\eta$ and is expressed as:

$$
\begin{aligned}
& \eta=\frac{i_{g}{ }^{*}-i_{g}}{i_{g}{ }^{*}} \\
& \text { Then, } \eta=\frac{1}{1+G(s)}
\end{aligned}
$$

So, at $\omega_{1}$, open loop transfer function and phase-response of the PR controller will be given by (11) and (13) respectively as:

$$
\begin{aligned}
& \left|G\left(j \omega_{1}\right)\right|=\frac{1}{\eta}-1 \\
& P R(s)=\frac{s^{2}+2 \omega_{b} s\left(1+\frac{K_{r}}{K_{P}}\right)+\omega_{1}^{2}}{s^{2}+2 \omega_{b} s+\omega^{2}} \\
& \Phi(\omega)=K_{p}+\frac{2 K_{r} \omega_{b} s}{s^{2}+2 \omega_{b} s+\omega_{1}^{2}} \\
& \Phi(\omega)=\operatorname{Tan}^{-1}\left(\frac{2 \omega_{b} \omega\left(1+\frac{K_{r}}{K_{P}}\right)}{\omega_{1}^{2}-\omega_{c}^{2}}\right)-\operatorname{Tan}^{-1}\left(\frac{2 \omega_{b} \omega}{\omega_{1}^{2}-\omega_{c}^{2}}\right)
\end{aligned}
$$

For stability, $\Phi\left(\omega_{c}\right)>-\Phi$

$$
\begin{aligned}
& \text { Or, }\left\{\operatorname{Tan}^{-1}\left(\frac{2 \omega_{b} \omega_{c}\left(1+\frac{K_{r}}{K_{P}}\right)}{\omega_{1}{ }^{2}-\omega_{c}^{2}}\right)-\operatorname{Tan}^{-1}\left(\frac{2 \omega_{b} \omega_{c}}{\omega_{1}^{2}-\omega_{c}^{2}}\right)\right\}>-\Phi \\
& \mid L\left(\omega_{1}\left|G\left(j \omega_{1}\right)\right|-\omega_{C}\left|\leq K_{r} \leq\right| K_{P}\left\{\left(\frac{\omega_{1}^{2}-\omega_{c}^{2}}{2 \omega_{b} \omega_{c}}\right) \operatorname{Tan}\left\{\operatorname{Tan}^{-1}\left(\frac{2 \omega_{b} \omega_{c}}{\omega_{1}{ }^{2} \omega_{c}^{2}}\right)-\Phi\right\}-1\right\} \mid\right.
\end{aligned}
$$

According to Eq. (15) minimum and maximum threshold limits of PR controller can be defined by Eq. (16) and (17) respectively: 


$$
\begin{aligned}
& K_{r_{-} \min _{x}}=\mid L\left(\omega_{1}\left|G\left(j \omega_{1}\right)\right|-\omega_{C} \mid\right. \\
& K_{r_{-} \max _{*}}=\left|K_{P}\left\{\left(\frac{\omega_{1}^{2}-\omega_{c}^{2}}{2 \omega_{b} \omega_{c}}\right) \tan \left\{\tan ^{-1}\left(\frac{2 \omega_{b} \omega_{c}}{\omega_{1}^{2} \omega_{c}^{2}}\right)-\Phi\right\}-1\right\}\right|
\end{aligned}
$$

\section{RESULTS AND DISCUSSION}

System parameters taken for simulation are given in Table I. Cut-off frequency is always less than one-tenth of the switching frequency [33], thus cut-off frequency is selected to be $1000 \mathrm{~Hz}$.

Table I. System Parameters

\begin{tabular}{|l|l|}
\hline Name & Value \\
\hline Switching Frequency & $10 \mathrm{KHz}$ \\
\hline Fundamental frequency & $50 \mathrm{~Hz}$ \\
\hline Grid Phase voltage & $230 \mathrm{~V}$ \\
\hline L filter inductor & $6 \mathrm{mH}$ \\
\hline
\end{tabular}

Using Eq. (6) and the values given in Table $1, K_{\mathrm{p}}$ is calculated to be approximately 38 . Consider steady-state error in injected grid current, $\eta=1 \%$.

From Eq. (11),

Open-loop transfer function of PR controller at fundamental frequency:

$\left|G\left(j \omega_{1}\right)\right|=99$.

Evaluating (16) and (17) yields to:

$$
K_{r_{-} \min _{\mathrm{x}}}=149 \text { and } K_{r_{-} \max .}=2000 .
$$

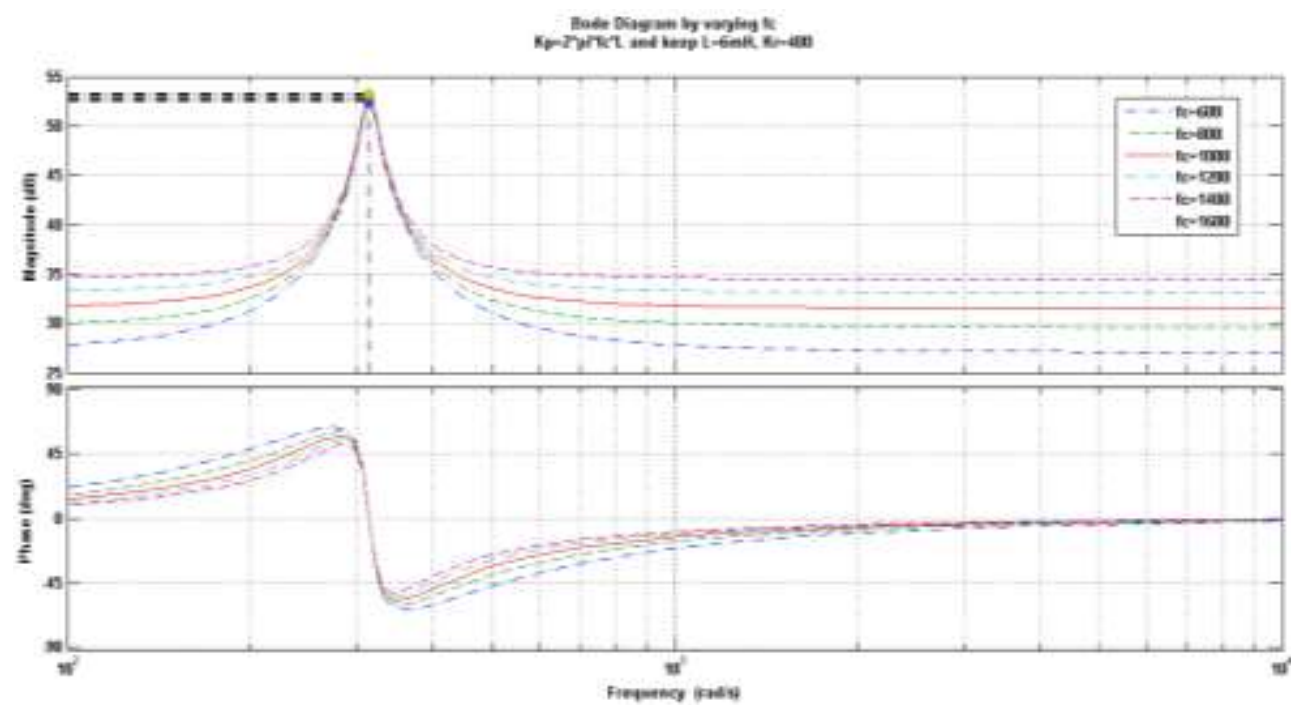

(a) 


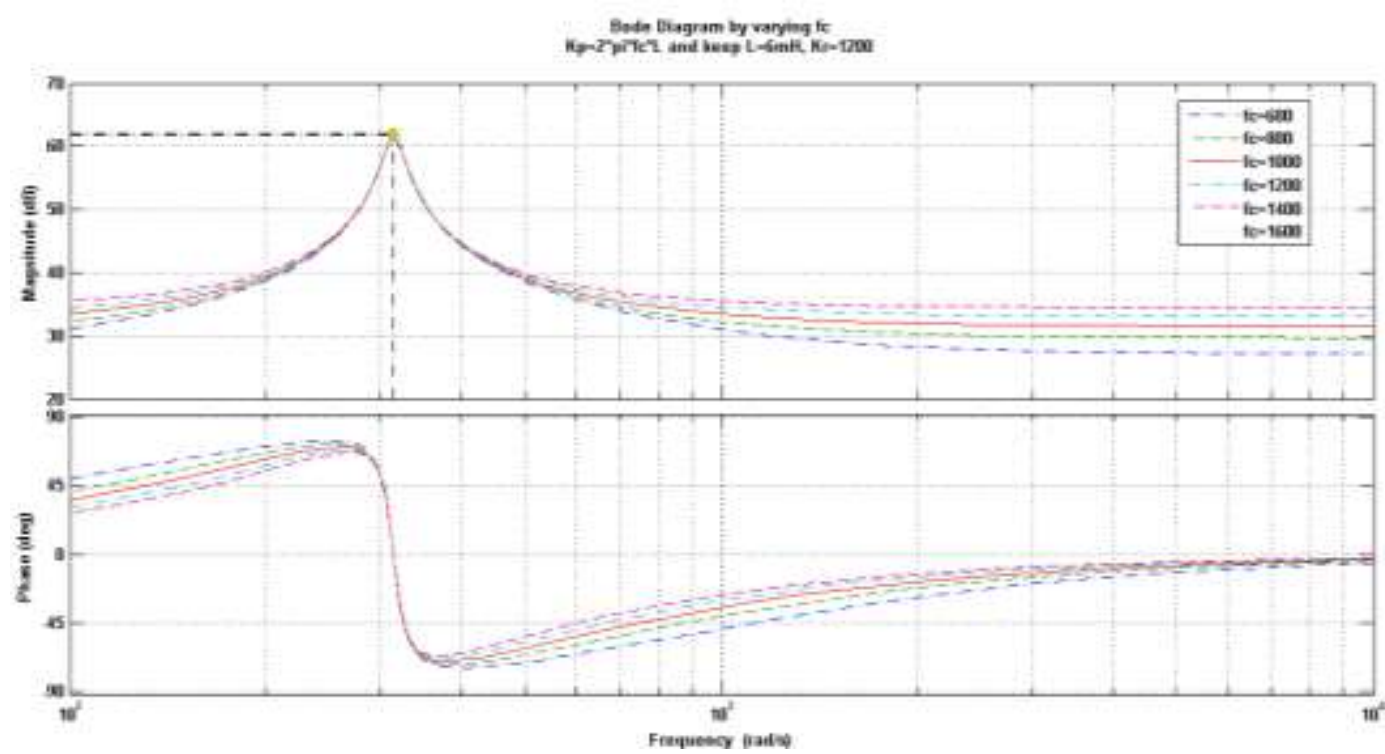

(b)

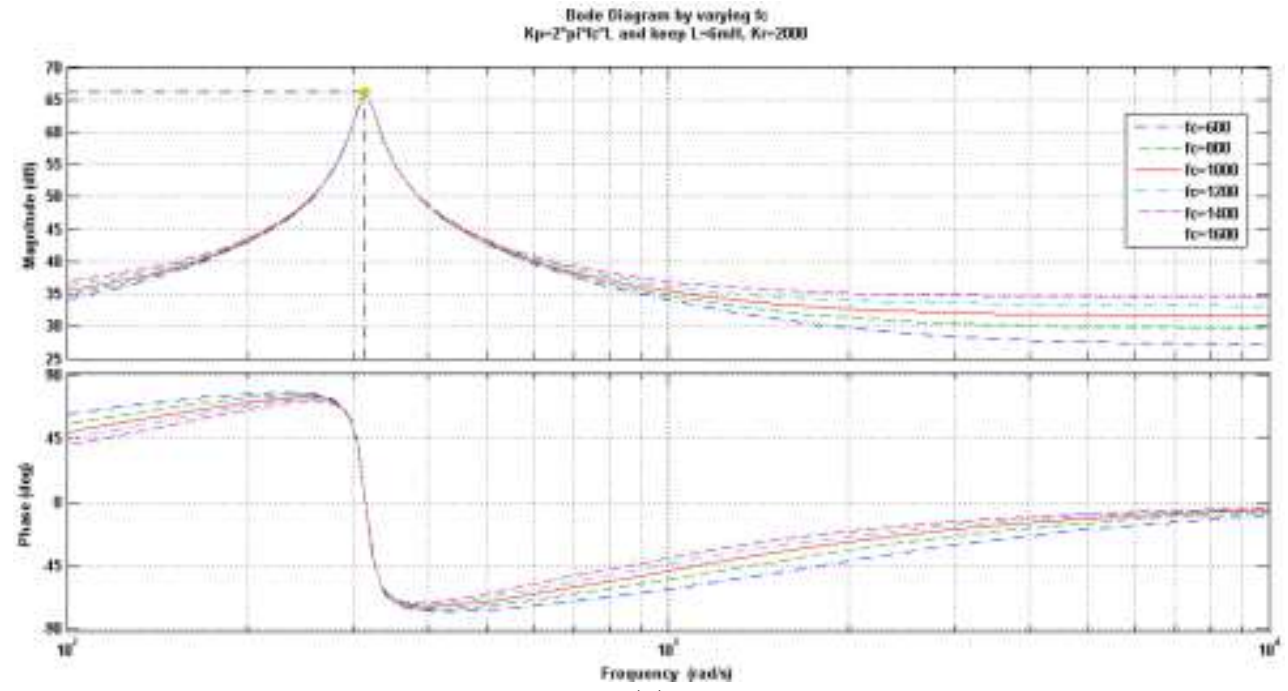

(c)

Fig. 5 Effect of varying $\mathrm{Kr}$ on open-loop bode plots for PR regulator by varying $\mathrm{f}_{\mathrm{c}}$ Values

Cut-off frequency allows the degree of freedom in the design of the frequency response of resonant controllers. Therefore, an increase in its value broadens the bandwidth, as illustrated in Fig. 5(a), Fig. 5(b) and Fig. 5(c). Bandwidth is further increased with the increase in $K_{r}$ value from 400 to 2000 in Fig. 5(a) to Fig. 5(b). For a particular resonant term, the peak amplitude remains the same irrespective of the changes in cut-off frequency, whereas this magnitude increases with increase in $\mathrm{Kr}$ value. For $\mathrm{K}_{\mathrm{r}}=$ 400 , peak amplitude is around $53 \mathrm{db}$ and it is increased to about $66 \mathrm{db}$ for $\mathrm{K}_{\mathrm{r}}=2000$. The same is illustrated in Fig. 6(a), Fig. 6(b) and Fig. 6(c). 


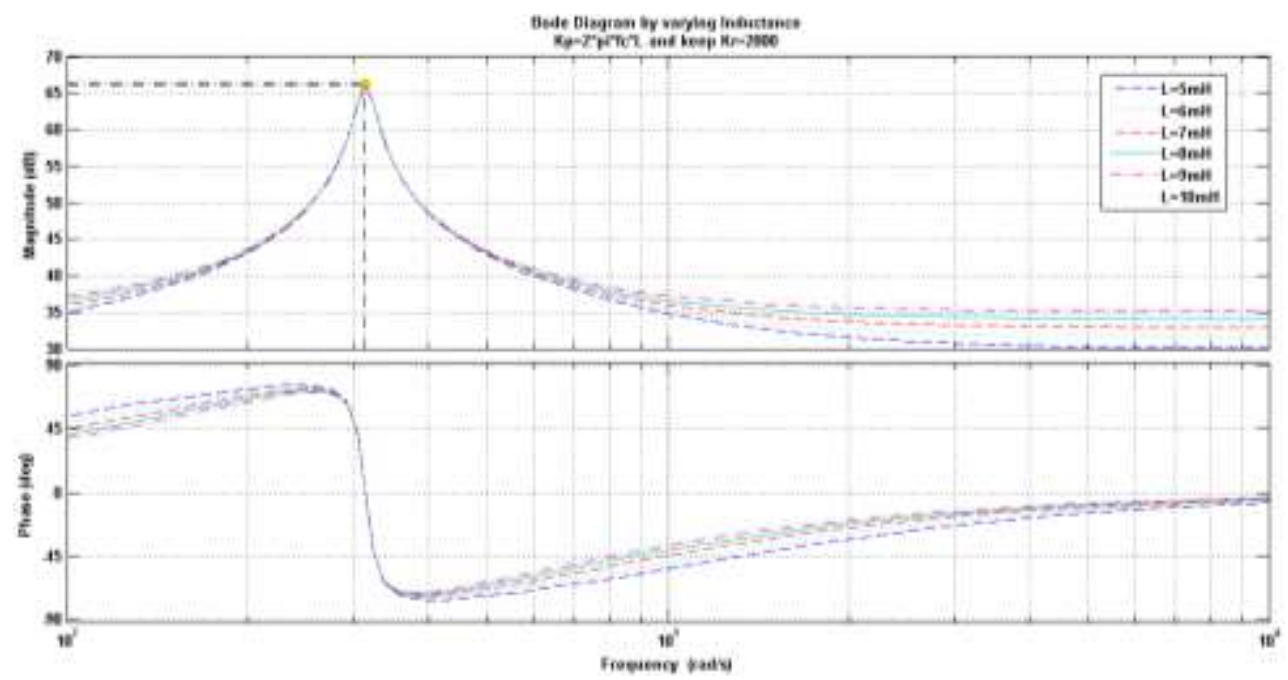

Fig. 6(a)

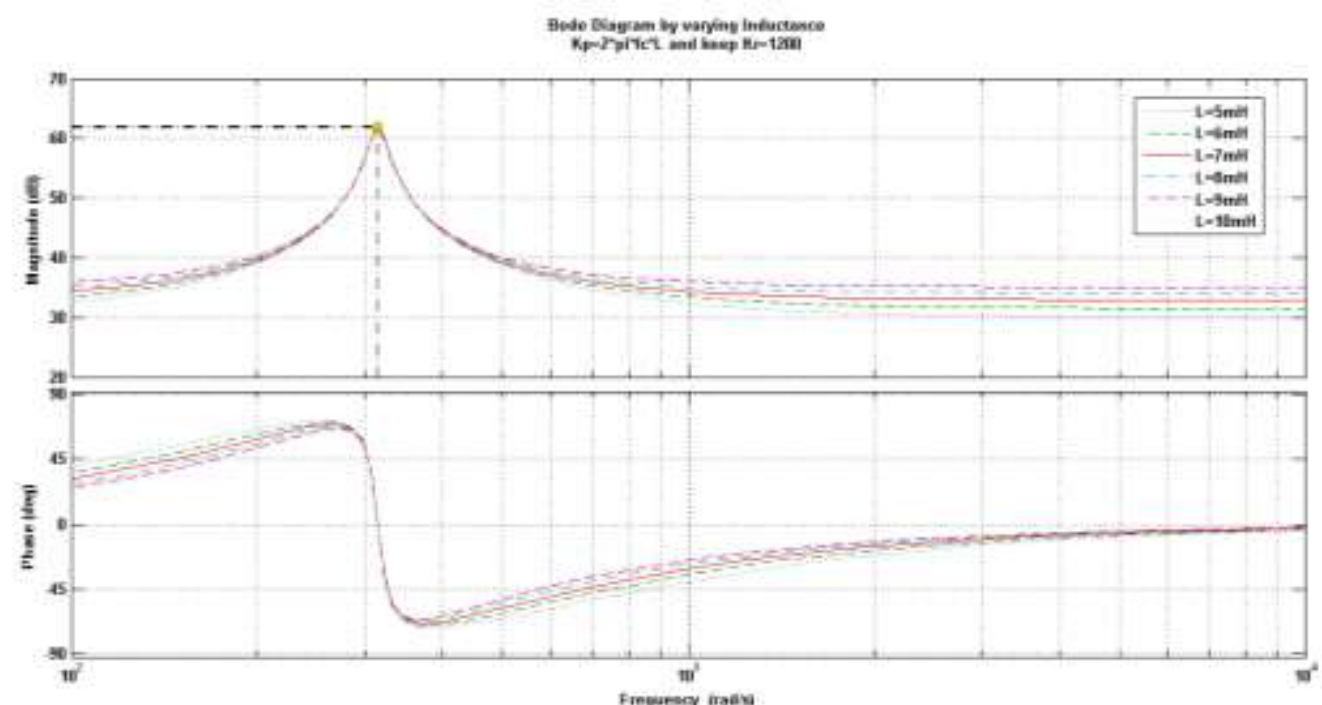

(b)

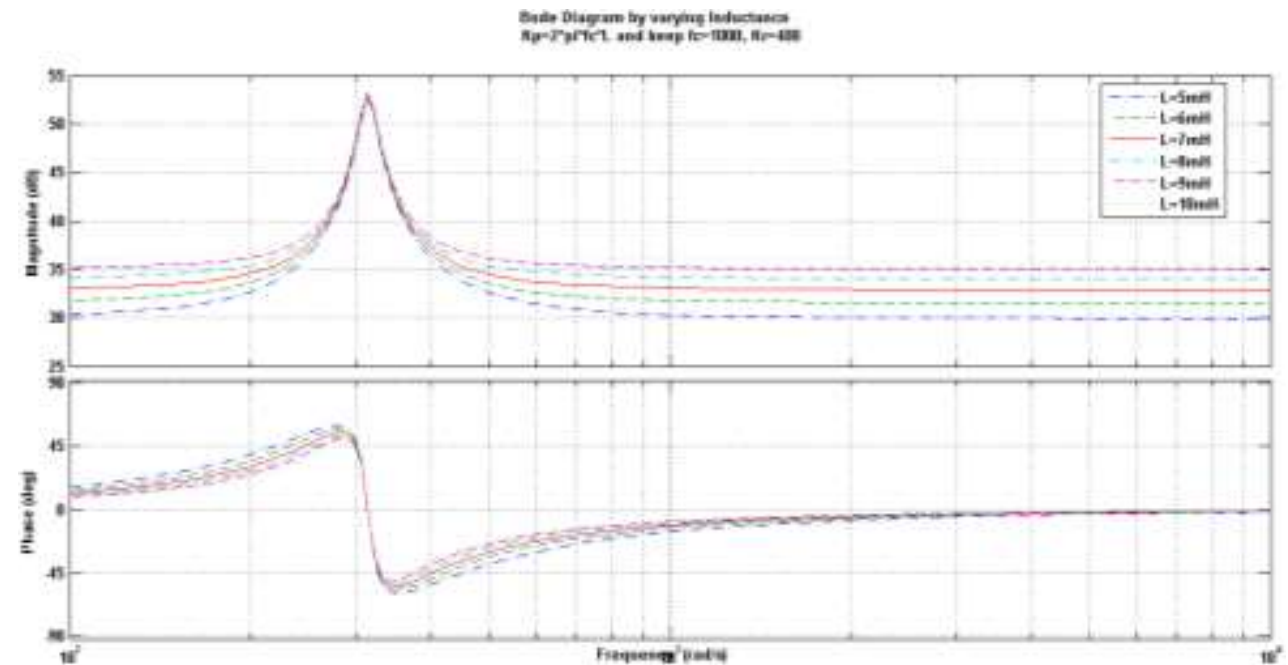

(c)

Fig. 6 Effect of varying $K_{p}$ on open-loop bode plots for PR regulator by varying $L$ values 


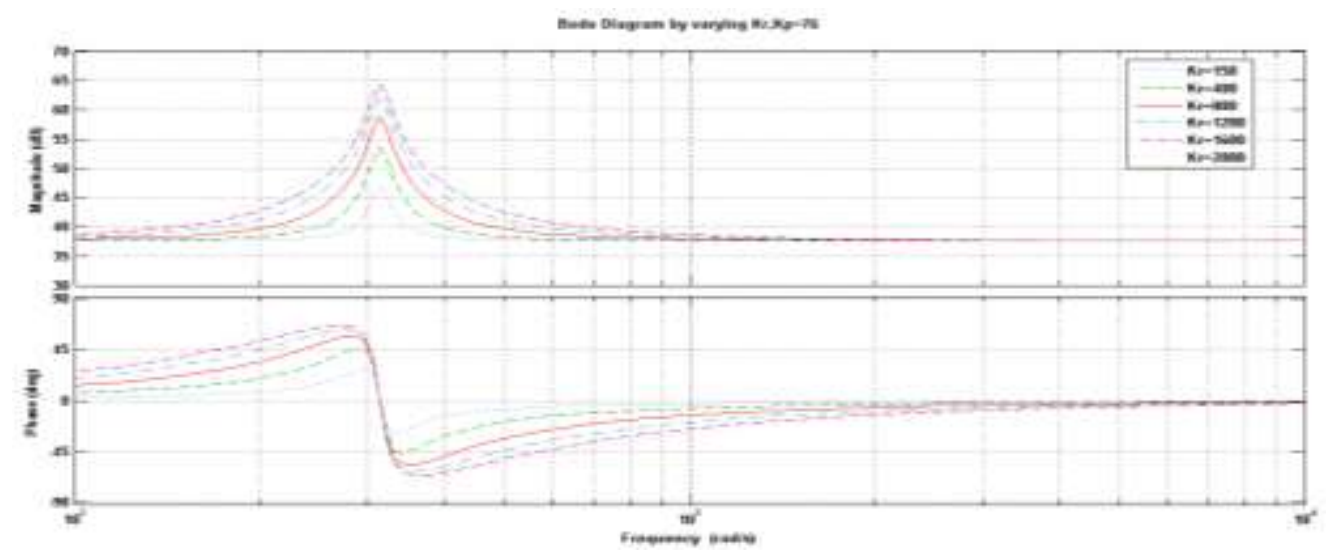

Fig. 7. Effect of varying $K_{r}$ on Open-loop bode plots for PR regulator

Fig. 7 highlights that amplitude at a particular frequency is increased by increasing the value of resonant term, $\mathrm{K}_{\mathrm{r}}$. $\mathrm{K}_{\mathrm{r}}$ also controls the bandwidth of the system around this particular frequency.

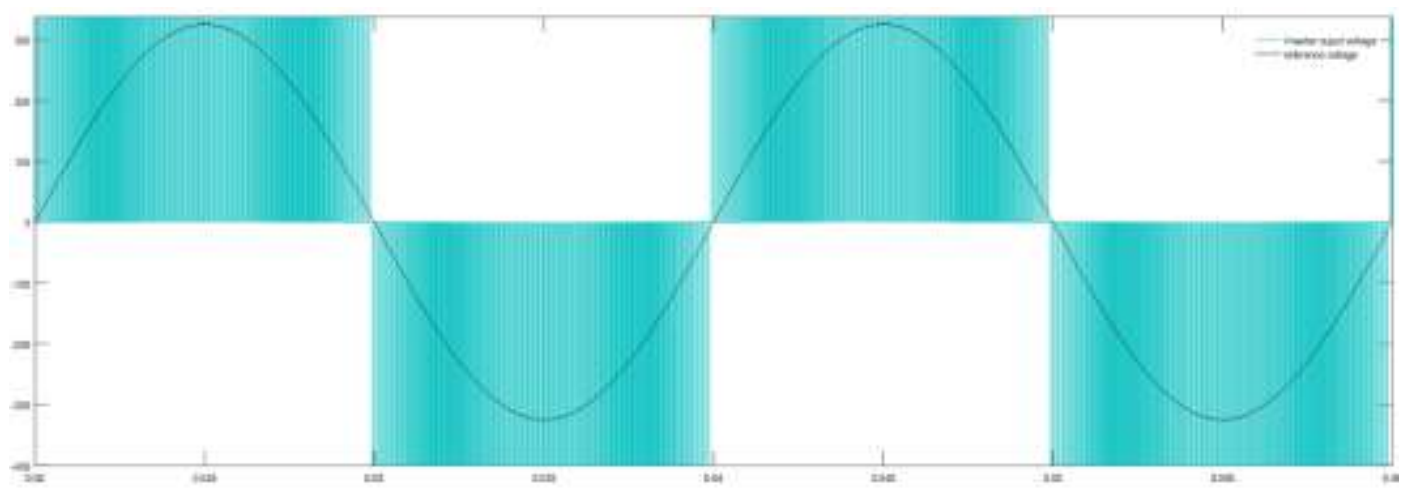

Fig. 8 Grid voltage and inverter output voltage

Fig. 9 and Fig. 10 show that for a pure resistive load the PR controller enables the perfect tracking of the injected grid current to the variations in the reference current at $\mathrm{t}=0.1 \mathrm{sec}$. It tracks the grid current completely in $4 \mathrm{~ms}$ for step change in grid current from 5 to $10 \mathrm{~A}$ at $\mathrm{t}=0.1 \mathrm{sec}$, as illustrated in Fig. 9. For better understanding of the grid voltage and current, grid voltage is scaled down by 30 in Fig. 10 and scaled down by 10 in Fig. 10.

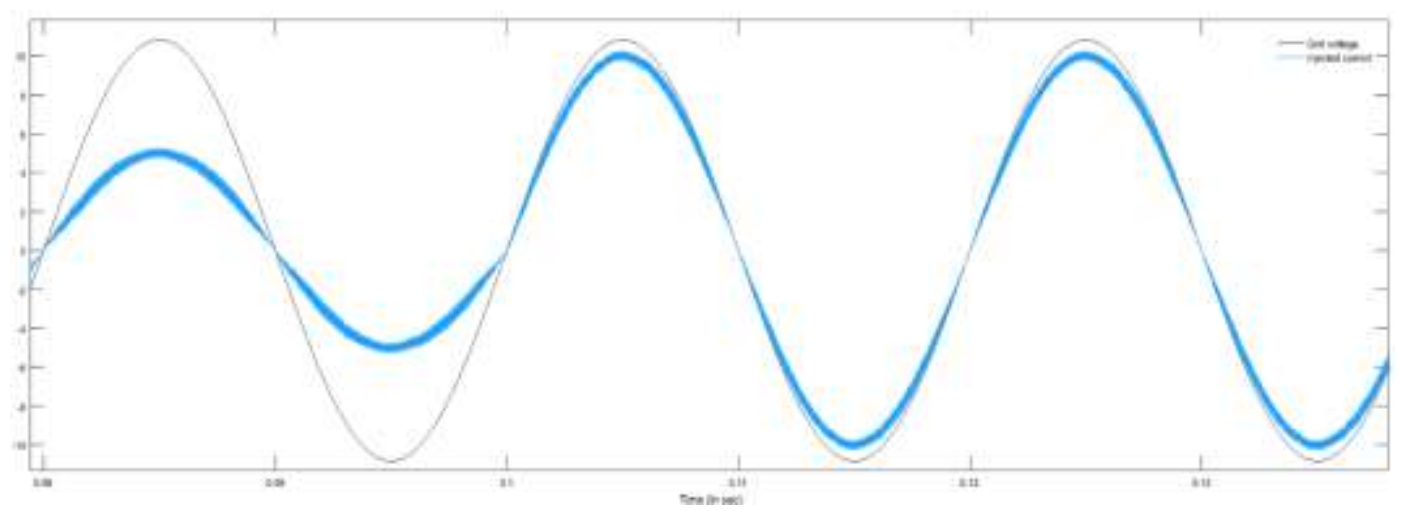

Fig. 9 Grid voltage (scaled down) and injected current when reference current is increased from $5 \mathrm{~A}$ to $10 \mathrm{~A}$ at $\mathrm{t}=0.1 \mathrm{sec}$. 


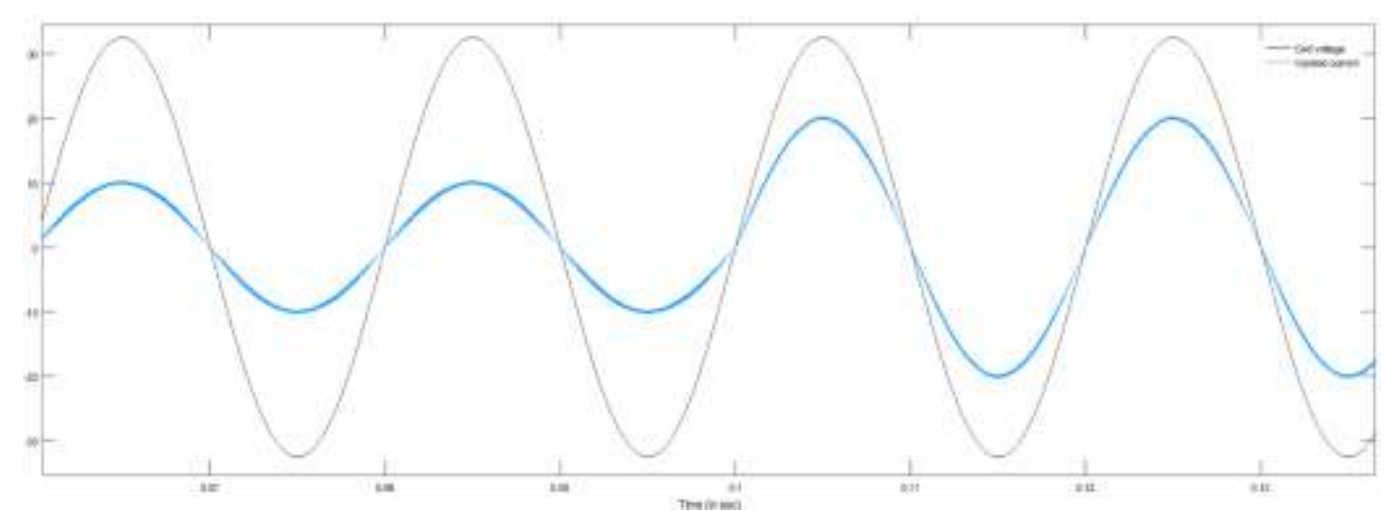

(b)

Fig. 10. Grid voltage (scaled down) and injected current when reference current is increased from $10 \mathrm{~A}$ to $20 \mathrm{~A}$ at $\mathrm{t}=0.1 \mathrm{sec}$

The current tracking ability by the designed PR controller is compare with PI controller described in [34]. For a step change in grid current, ripple of $16 \%$ in the converter current is obtained with the implementation of [34]. Whereas the PR controller presented in this paper demonstrates a superior performance with reduced ripple in converter current and faster tracking of grid current.

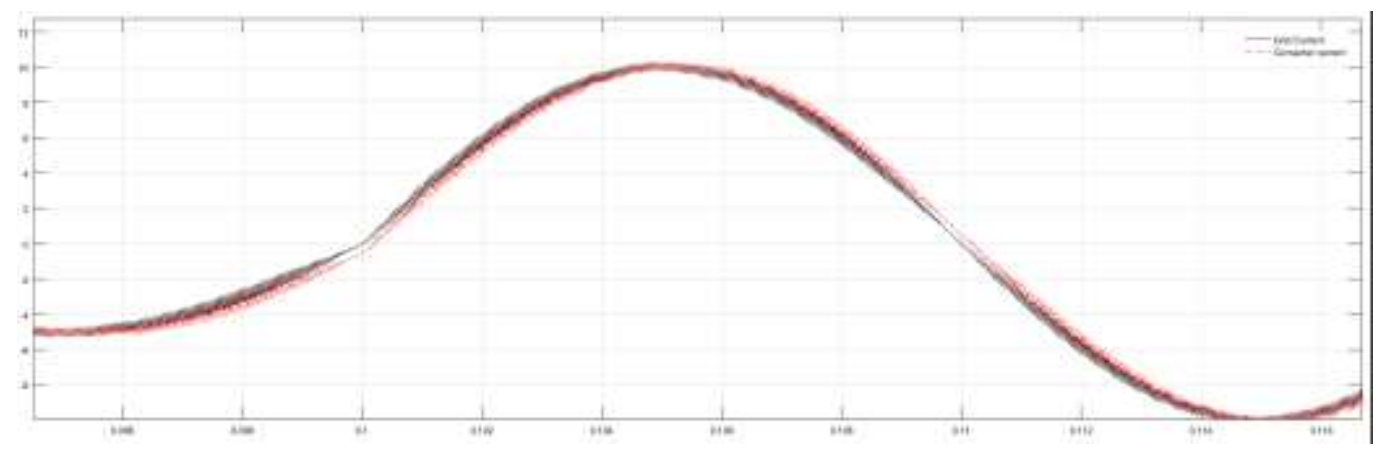

Fig. 9 Current tracking by PR controller for step change in grid current

\section{CONCLUSION}

This paper presents the need for a Proportional resonant controller in a single-phase grid connected system and also details diagnostic approach the steps to design the PR controller. Using the numerical results from the design process, simulations are performed and extensive studies are carried out using bode diagrams by varying the system parameters. It was demonstrated that $\mathrm{Kr}$ also controls the bandwidth of the system around a particular frequency and amplitude at this frequency increases with increasing $\mathrm{Kr}$ value. Moreover, for a particular resonant term, the peak amplitude remains the same irrespective of the changes in cut-off frequency. Simulation results show that the injected current follows the variations in the reference current

\section{REFERENCES}

[1] Anand Mishra, The Review of Trends in Smart Grid and its Applications, International Journal of Cloud-Computing and Super-Computing. Vol. 4. No. 1. Jun. 2017.GVPress. pp:2734.http://dx.doi.org/10.21742/IJCS.2017.4.1.05

[2] Gussan Mufti, Mohsin Jamil, Raheel Afzal, Muhammad Arifeen Ali and Asim Waris, "Design and Analysis of Optimal Controllers for Grid Connected Inverters for Photovoltaic Applications", International Journal of Control and Automation, SERSC Australia, ISSN: 2005-4297 (Print); 22076387 (Online), vol. 9, no. 10, October (2016), pp.229-236, http://dx.doi.org/10.14257/ijca.2016.9.10.22. 
[3] D. Narasimha Rao and Sk. Moulali.SVPWM implementation of three phase four leg inverter for grid interfacing converter systems.International Journal of Wireless and Mobile Communication for Industrial Systems. Vol. 3. No. 1. Apr. 2016.GVPress. pp:112.http://dx.doi.org/10.21742/IJWMCIS.2016.3.1.01

[4] K V Siva Reddy and SK.Moulali, Reduction of Power Oscillations in Grid Connected DG with Proper Design of Compensator, International Journal of Energy, Information and Communications. Vol. 8. No. 5. Oct. 2017.GVPress. pp:13-20.http://dx.doi.org/10.21742/IJEIC.2017.8.5.02.

[5] A.Elrheem E.A. Mostafa, Naglaa K. Bahgaat, Mohamed Ebrahim El sayed and El-Said A. Othman, "Voltage Stability for a Photovoltaic System Connected to Grid by Using Genetic Algorithm Technique", International Journal of Grid and Distributed Computing, SERSC Australia, ISSN: 20054262 (Print); 2207-6379 (Online), vol.10, no.4, April (2017), pp. 33-42, http://dx.doi.org/10.14257/ijgdc.2017.10.4.04.

[6] Ngoc Bao Lai and Kyeong-Hwa Kim, "Simple and Reliable Harmonic Mitigation Strategy in Power Electronic Converter for Grid Integration of Renewable Energy Resources", International Journal of Control and Automation, SERSC Australia, ISSN: 2005-4297 (Print); 2207-6387 (Online), vol. 10, no. 2, February (2017), pp.75-88, http://dx.doi.org/10.14257/ijca.2017.10.2.07.

[7] He Tao , Liang Zhidong, Ye Xinquan, Sun Shufengand Pang Jihong, "Modeling and Parameter Estimation of Particle Swarm Optimization Algorithm for Smart Power Grid", International Journal of Grid and Distributed Computing, SERSC Australia, ISSN: 2005-4262 (Print); 2207-6379 (Online), vol.8, no.6, December (2015), pp. 229-238, http://dx.doi.org/10.14257/ijgdc.2015.8.6.22

[8] Virendra Sharma and Lata Gidwani, "Frequency Regulation of Electric Grid with Wind Power Using Energy Storage System ", International Journal of Grid and Distributed Computing, SERSC Australia, ISSN: 2005-4262 (Print); 2207-6379 (Online), vol.8, no.3, June (2015), pp. 267-274, http://dx.doi.org/10.14257/ijgdc.2015.8.3.26.

[9] Yongqi Tang and Xuan Lin, "Application of Fuzzy PI Controller for Wind Power Grid-connected Inverter", International Journal of Control and Automation, SERSC Australia, ISSN: 2005-4297 (Print); 2207-6387 (Online), vol. 9, no. 12, December (2016), pp.125-138, http://dx.doi.org/10.14257/ijca.2016.9.12.12.

[10] Jin-Gyu Chang and Moon-Sik Kang, "Implementation of an Optimal Control System of Distributed Power Using Microgrid Based Load Prediction Method", International Journal of Future Generation Communication and Networking, SERSC Australia, ISSN: 2233-7857 (Print); 2207-9645 (Online), vol. 10, no. 9, September (2017), pp. 97-106, http://dx.doi.org/10.14257/ijfgen.2017.10.9.08.

[11] Kazmierkowski, M., Krishnan, R., and Blaabjerg, F., Control in power electronics. Selected problems. (Academic Press, 2002)

[12] RamaKoteswara Rao Alla, J. S. Lather and G. L. Pahuja, "PI Controller Performance Analysis Using Lambert W Function Approach for First Order Systems with Time Delay", International Journal of Advanced Science and Technology, SERSC Australia, ISSN: 2005-4238 (Print); 2207-6360 (Online), vol. 86, January (2016), pp. 1-8, http://dx.doi.org/10.14257/ijast.2016.86.01.

[13] Liserre, M., Blaabjerg, F., and Hansen, S., "Design and control of an LCL-filter based active rectifier", IEEE Trans. Industrial Applications, 2001, 38, pp. 299-307.

[14] Lianqing Zheng, Chen Zhuang, Jian Zhang and Xiong Du, "An Enhanced Droop Control Scheme for Islanded Microgrids", International Journal of Control and Automation, SERSC Australia, ISSN: 20054297 (Print); 2207-6387 (Online), vol. 8, no. 4, April (2015), pp. 63-74, http://dx.doi.org/10.14257/ijca.2015.8.4.08.

[15] Jae Jung Kim.Bandwidth Estimation of Networks with Random Service.International Journal of Communication Technology for Social Networking Services . Vol. 5. No. 1. Mar. 2017.GVPress. pp:16.http://dx.doi.org/10.21742/IJCTSNS.2017.5.1.01

[16] Gao Jie, Wang Jia and Zhou Yang, "Low Frequency Oscillation Modal Parameter Identification Based on NExT-ERA and Fuzzy Clustering", International Journal of Control and Automation, SERSC Australia, ISSN: 2005-4297 (Print); 2207-6387 (Online), vol. 9, no. 1, January (2016), pp.309-322, http://dx.doi.org/10.14257/ijca.2016.9.1.28.

[17] RSR Sankar, SVJ Kumar, GM Rao, Impedance based stability analysis of single-phase PV inverter connected to weak grid with voltage feed forward control,2017 IEEE International Conference on Power, Control 2017.

[18] Seung-Mook Baek, "Sensitivity Analysis Based Optimization for Linear and Nonlinear Parameters in AVR to Improve Transient Stability in Power System", International Journal of Control and Automation, SERSC Australia, ISSN: 2005-4297 (Print); 2207-6387 (Online), vol. 8, no. 7, July (2015), pp. 167-174, http://dx.doi.org/10.14257/ijca.2015.8.7.18.

[19] Deepak Kumar Lal, Ajit Kumar Barisal and Manish Tripathy, "Load Frequency Control of Multi Source Multi-Area Nonlinear Power System with DE-PSO Optimized Fuzzy PID Controller in Coordination with SSSC and RFB", International Journal of Control and Automation, SERSC Australia, ISSN: 2005 4297 (Print); 2207-6387 (Online), vol. 11, no. 7, July (2018), pp.61-80, http://dx.doi.org/10.14257/ijca.2018.11.7.06.

[20] Dan Zhao, Hongyu Zhang, Yue Han and Zisong Xiao, "Sliding Mode Control for Nonlinear Systems Based on Singular Value Decomposition", International Journal of Control and Automation, SERSC 
Australia, ISSN: $2005-4297$ (Print); 2207-6387 (Online), vol. 8, no. 11, November (2015), pp. 1-12, http://dx.doi.org/10.14257/ijca.2015.8.11.01.

[21] R S Ravi Sankar, S V Jayaram Kumar, K K Deepika, "Model Predictive Current Control of Grid Connected PV Systems," Indonesian Journal of Electrical Engineering and Computer Science Vol. 2, No. 2, May 2016, pp. 285- 296.

[22] Thai-Thanh Nguyen, Hyeong-Jun Yoo and Hak-Man Kim, "Coordinated Frequency Control of FESS and BESS in Microgrid based on Model Predictive Control Strategy", International Journal of Control and Automation, SERSC Australia, ISSN: $2005-4297$ (Print); 2207-6387 (Online), vol. 10, no. 2, February (2017), pp.383-394, http://dx.doi.org/10.14257/ijca.2017.10.2.32.

[23] Jena, Satyaranjan \& Chitti Babu, B \& Naik, Amiya \& Mishra, Gokulananda. (2011). Performance improvement of single-phase grid - Connected PWM inverter using PI with hysteresis current controller. Proceedings - 2011 International Conference on Energy, Automation and Signal, ICEAS 2011. 10.1109/ICEAS.2011.6147101.

[24] Yuan, X., Merk, W., Stemmler, H., and Allmeling, J. 'Stationary frame generalized integrators for current control of active power filters with zero steady-state error for current harmonics of concern under unbalanced and distorted operating conditions', IEEE Trans. Industrial Applications, 2002, 38, pp. 523-532.

[25] G. Yepes, F. D. Freijedo, O. Lopez and Doval-Gandoy, "Analysis and Design of Resonant Current Controllers for Voltage-Source Converters by Means of Nyquist Diagrams and Sensitivity Function", IEEE Transactions on industrial Electronics, vol. 58, no. 11, pp. 5231-5250, Nov. 2011.

[26] Anirudh Budnar Acharya, Dezso Sera, Lars E Norum, Remus Teodorescu, "Frequency Adaptive Digital Filter Implementation of Proportional-Resonant Controller for Inverter Applications", 2018 IEEE 19th Workshop on Control and Modeling for Power Electronics (COMPEL),2018,pp:1-7.

[27] L. Harnefors, L. Zhang and M. Bongiorno, "Frequency-domain passivity-based current controller design", IET Power Electronics, vol. 1, no. 4, pp. 455-465, Dec. 2008.

[28] R. Teodorescu, F. Blaabjerg, M. Liserre and P. C. Loh, "Proportional-resonant controllers and filters for grid-connected voltage-source converters," in IEE Proceedings - Electric Power Applications, vol. 153, no. 5, pp. 750-762, September 2006.

[29] Cha, Hanju \& Vu, Trung-Kien \& Kim, Jae-Eon. (2009). Design and control of Proportional-Resonant controller based Photovoltaic power conditioning system. 2198 - 2205. 10.1109/ECCE.2009.5316374.

[30] Pereira, Luís \& Bazanella, Alexandre. (2015). Tuning Rules for Proportional Resonant Controllers. IEEE Transactions on Control Systems Technology. 23. 1-1. 10.1109/TCST.2015.2389655.

[31] Z. Ali, N. Christofides, L. Hadjidemetriou and E. Kyriakides, "Improved transient performance properties of distributed generation grid side converter current controller under grid voltage harmonic distortion and unbalanced faults," IECON 2017 - 43rd Annual Conference of the IEEE Industrial Electronics Society, Beijing, 2017, pp. 7783-7788.

[32] Daniel Nahum Zmood, Student Member, IEEE and Donald Grahame Holmes, Member, IEEE, "Stationary Frame Current Regulation of PWM Inverters with Zero Steady-State Error", IEEE TRANSACTIONS ON POWER ELECTRONICS, VOL. 18, NO. 3, MAY 2003, pp: 814-822.

[33] Dannehl, J., Wessels, C., Fuchs, F.W, "Limitations of voltage-oriented PI current control of gridconnected PWM rectifiers with LCL filters", IEEE Trans. Industrial Electronics, 2009, 56, 380-388.

[34] A. Ali, P. Shanmugham and S. Somkun, "Single-phase grid-connected voltage source converter for LCL filter with grid-current feedback," 2017 International Electrical Engineering Congress (iEECON), Pattaya, 2017, pp. 1-6. doi: 10.1109/IEECON.2017.8075720. 
International Journal of Control and Automation Vol. 12, No. 7 (2019) 